\section{Perfil sócio-epidemiológico demográfico das mulheres idosas da Universidade Aberta à Terceira Idade no estado de Pernambuco}

\section{Demographic social-epidemiological profile of elderly women enrolled at the Open University Program for Senior Citizens in the State of Pernambuco}

Kátia Magdala Lima Barreto 1

Eduardo Maia Freese de Carvalho 2

Ilka Veras Falcão 3

Fábio José Delgado Lessa 4

Valéria Moura Moreira Leite 5

1,3,5 Departamento de Terapia Ocupacional. Universidade Federal de Pernambuco. Av. Prof. Moraes Rego, 1.235.

Cidade Universitária. Recife, PE, Brasil. CEP: 50.670-420.

E mail: katmag@nlink.com.br

2 Departamento de Estudos em Saúde Coletiva. Centro de Pesquisa Aggeu Magalhães. Departamento de Medicina Social.

Universidade Federal de Pernambuco.

${ }_{4}^{4}$ Departamento de Estudos em Saúde Coletiva. Centro de Pesquisa

Aggeu Magalhães. Departamento de Fonoaudiologia da

Universidade Federal de Pernambuco.

\begin{abstract}
Objectives: to determine the demographic socialepidemiological profile of elderly women enrolled at the Open University Program for Senior Citizens, Federal University of Pernambuco (UnATI/PE), as compared to other studies focusing senior citizens' universities.

Methods: epidemiological descriptive cross sectional and census study comprised of 308 elderly women starting at 60 years old enrolled at the UnATI/UFPE. A multidimensional tool, Brazil Old Age Schedule consisting of a structured questionnaire was used through which personal and family, economic and social conditions and aspects related to autonomy and functional independence in the performance of day to day activities and leisure were investigated.

Results: in relation to personal and family situation, the younger group (60 to 69 years old), consisting of high-school graduates and widows prevailed. They demonstrated high levels of autonomy and functional independence, capability of accomplishing day to day chores on their own and instrumental activities of day to day life. The majority offers financial help and homes to other family members.

Conclusions: demographic social-epidemiological profile is very similar to the one of analogous experiments, close to the reality of elderly women enrolled at Open Universities for Senior Citizens programs.
\end{abstract}

Key words Aged, Women, Aging, Epidemiology

\section{Resumo}

Objetivos: identificar o perfil sócio-epidemiológico demográfico das mulheres idosas que freqüentam o Programa Universidade Aberta à Terceira Idade, da Universidade Federal de Pernambuco (UnATI/UFPE), comparando com determinados estudos sobre universidades da terceira idade.

Métodos: estudo epidemiológico descritivo de corte transversal e censitário com 308 idosas, a partir dos 60 anos, do UnATI/UFPE. Foi utilizado um instrumento multidimensional, o Brazil Old Age Schedule composto por um questionário estruturado, através do qual investigou-se a situação pessoal e familiar, a condição econômico-social e os aspectos relativos à autonomia e independência funcional para o desempenho das atividades de vida diária e à ocupação do tempo livre.

Resultados: em relação à situação pessoal e familiar, predominam as idosas jovens (60 a 69 anos), com escolaridade de segundo grau completo, cuja maioria é viúva; referem satisfação com a vida; apresentam importantes níveis de autonomia e independência funcional; são capazes de realizar sozinhas as atividades de vida diária e as atividades instrumentais vida diária. A maior parte oferece a seus familiares ajuda financeira e de moradia.

Conclusões: os perfis sócio-epidemiológico e demográfico são bastante semelhantes aos de experiências análogas, aproximando-se da realidade de mulheres idosas que participam de outros programas do tipo Universidades Abertas à Terceira Idade.

Palavras-chave Idoso, Mulheres, Envelhecimento, Epidemiologia 


\section{Introdução}

Nunca antes, na história da humanidade, o ser humano alcançou idades tão avançadas. Do ponto de vista social, Debert ${ }^{1}$ identifica que a maioria dos relatos refere uma velhice abandonada, solitária e empobrecida, relegada a um plano secundário nas sociedades industrializadas. Segundo a autora, com o envelhecimento passando a ser visto como uma experiência mais gratificante, tem-se observado no Brasil uma série de trabalhos que valorizam essa vivência coletiva, como, por exemplo, os programas de universidades abertas para a terceira idade que, na década de noventa, proliferaram por todo o país.

Entre alguns recortes que procuram definir velhice, o cronológico tem sido aceito praticamente de forma unânime. Para fins de pesquisa e legislação, porém devemos guardar suas limitações como indicador de velhice. $\mathrm{O}$ aumento acelerado da população idosa e seu impacto para os diversos setores da sociedade têm sido discutidos nos meios políticos e acadêmicos, com o objetivo de encontrar soluções viáveis para o enfrentamento dessa realidade que se impõe a um país como o Brasil. Dessa forma, apesar de se observar, no país, um franco processo de envelhecimento populacional, deve-se considerar também o grande número de jovens em uma população em crescimento demográfico. Essa situação gera uma polarização de demandas, exigindo planejamento para equacionar a destinação de recursos e ações públicas. ${ }^{2}$

O processo de envelhecimento populacional experimentado no Brasil é um dos mais acelerados do mundo. Devemos passar, em termos proporcionais, de 7,3\%, em 1971, ou seja, de 11 milhões de idosos, para $15 \%$, em 2025 , ou seja, para 32 milhões de idosos, colocando o Brasil, nesse período, como a sexta população de idosos do mundo em números absolutos. $^{3}$

A população de 60 anos e mais, no Recife, representa $9,38 \%$ em relação à população total. Vale ressaltar que é importante o aumento da proporção de mulheres idosas nas faixas de idade mais avançadas. ${ }^{4}$

Para Carvalho et al., 5 a exemplo de muitos países em desenvolvimento, o Brasil, que, apesar de contar com alguma melhoria dos indicadores sobre as condições gerais de vida, não pode atribuir exclusivamente a essas condições o rápido envelhecimento da sua população. Na realidade, conquistas setoriais, por exemplo, assistência médica e emprego de tecnologias, como vacinas e saneamento básico, são determinantes para esse novo perfil demográfico no país. Entretanto deve-se considerar que o atual perfil epidemiológico ainda está pautado num contexto de iniquiidade social decorrente de causas estruturais, políticas e econômicas na sociedade brasileira. O atual perfil epidemiológico caracteriza-se, pois, simultaneamente pela presença de enfermidades crônicas e degenerativas, altos índices de enfermidades infecciosas e parasitárias, elevadas taxas de violência e ainda enfermidades emergentes ou re-emergentes.

Carvalho et al. ${ }^{5}$ referem, ainda, que esse processo de mudança de perfil epidemiológico denominase, no campo da saúde coletiva, de transição epidemiológica. Nesse sentido, a situação observada identifica que o processo de transição epidemiológica ainda não está devidamente garantido. Isso se deve a um processo histórico diferente do ocorrido nos chamados países desenvolvidos, posto que não se observa no Brasil uma situação definida de transição, mas um novo padrão epidemiológico com uma modernidade duvidosa, que difere do observado no contexto internacional.

Entretanto, o contexto demográfico evidencia, num processo de transição já definido e assegurado, um número crescente de idosos na população, determinando socialmente uma grande demanda por recursos médico-assistencial-previdenciários para atendêlos. Nesse sentido, apesar de se observar uma maior prevalência de doenças crônicas em uma população envelhecida, o conceito de saúde que se defende para os idosos está ligado à sua capacidade funcional e não apenas à presença ou não de uma patologia crônica, mesmo quando essa vem acompanhada de incapacidade associada. Para fins de planejamento, essa abordagem é extremamente útil, pois, nos países em desenvolvimento, devido à grande desigualdade social, o critério cronológico torna-se insuficiente, uma vez que muitas vezes o envelhecimento funcional antecede o envelhecimento cronológico. ${ }^{2}$

Portanto, diante do cenário do envelhecimento populacional no Brasil, em que, de um lado, ainda se tem um grande quantitativo de população jovem e, de outro, um rápido e intenso envelhecimento populacional em condições sócio-sanitárias desfavoráveis, Ramos ${ }^{6}$ propõe que tal realidade deva ser considerada uma questão de Saúde Pública, o que exige soluções viáveis do ponto de vista social, político e econômico. Todavia, propor ações para a terceira idade, no Brasil, torna-se tarefa difícil, já que os recursos para o desenvolvimento de políticas públicas são sempre escassos.7

A recente legislação relativa aos direitos dos idosos no país, a Lei nº 8842 de 4 janeiro de 1994, que dispõe sobre a Política Nacional do Idoso, recomenda, no que compete ao Ministério da Educação, o incentivo à criação de Universidades Aber- 
tas à Terceira Idade nas Instituições de Ensino Superior (inciso III do art. 10). 8

A experiência pioneira nesse sentido ocorreu em 1977, no, Serviço Social do Comércio (SESC) em São Paulo, SP com a criação da Escola Aberta para a Terceira Idade; em 1990, a Pontifícia Universidade Católica de Campinas criou sua Universidade para a Terceira Idade. Na década de 90, essas experiências se multiplicaram por vários estados brasileiros. ${ }^{9}$

Nessa perspectiva, foi criado, em setembro de 1996, o Programa Universidade Aberta à Terceira Idade, da Universidade Federal de Pernambuco. Trata-se de uma microuniversidade temática, que aborda as questões do envelhecimento, através de atividades de ensino, pesquisa e extensão. Tem como objetivo principal promover a integração universidadeidoso-comunidade, envolvendo vários segmentos da comunidade universitária e da comunidade em geral.10

Considerando a Universidade um espaço potencial para responder a essas demandas, julgamos relevante a investigação realizada com um grupo de mulheres idosas que freqüentam o Programa Universidade Aberta à Terceira Idade. Esse Programa, por ser o único no Estado, só nos permite comparações com estudos realizados em outras Instituições de Ensino Superior no Brasil e no exterior.

O Programa da Universidade Federal de Pernambuco tem como constituinte uma população formada por pessoas a partir de 60 anos, o que difere de algumas experiências análogas, que admitem pessoas com idade inferior a essa. Realizamos uma investigação sócio-epidemiológica demográfica com o grupo de idosos que freqüentam o Programa, acreditando que, conhecendo-se o perfil desse grupo, será possível uma aproximação da caracterização da população idosa que freqüenta programas especiais a ela destinados, podendo nortear futuras experiências e apontar possibilidades para formulação de propostas relativas aos programas para a terceira idade.

Devido à grande proporção de mulheres $(86,03 \%)$, no censo realizado, refletindo uma situação observada universalmente em outros estudos sobre Universidades para a Terceira Idade, decidimos, para este artigo, fazer um recorte de gênero.

Nesse sentido, definimos como objetivo do estudo identificar o perfil sócio-epidemiológico demográfico das mulheres idosas que freqüentam o Programa Universidade Aberta à Terceira Idade, analisando sua situação pessoal e familiar, sua condição econômico-social e os aspectos relativos à autonomia e independência funcional para o desempenho das atividades de vida diária (AVDs) e à ocupação do tempo livre, em comparação com determi- nados estudos sobre universidades da terceira idade.

\section{Métodos}

Trata-se de um estudo epidemiológico descritivo de corte transversal, em que foi realizado um censo com 308 idosas que freqüentam o Programa Universidade Aberta à Terceira Idade da Universidade Federal de Pernambuco, (UnATI/UPE) em Recife, Brasil.

Para os propósitos deste estudo, decidimos utilizar o critério cronológico, ou seja, foram consideradas idosas todas as mulheres com 60 anos ou mais, definido a priori, uma vez que é requisito do Programa UnATI/UFPE a admissão de pessoas a partir dos 60 anos.

Utilizamos um instrumento multidimensional, já validado no Brasil - o Brazil Old Age Schedule (BOAS) composto por um questionário estruturado em que é possível investigar a situação social e familiar, a utilização de serviços de assistência de saúde, o desempenho nas atividades de vida diária, a ocupação do tempo livre, os recursos econômicos e sociais, a saúde física e mental. Para efeito deste artigo, utilizamos as seções que tratam da situação social e familiar, do desempenho nas atividades de vida diária, da ocupação do tempo livre e das condições econômicas e sociais.

Os estudos com os quais comparamos nossos achados são para idosos de ambos os sexos, porém, como as idosas da UnATI/UFPE representam $86,03 \%$ em relação ao total do grupo, - resultado este semelhante ao perfil de outros programas análogos, - não haverá comprometimento das comparações aqui apresentadas. Ressalte-se que algumas dessas expe-riências similares admitem pessoas com menos de 60 anos.

\section{Resultados}

\section{Perfil sócio-epidemiológico demográfico}

Entre as 308 idosas estudadas, $220(71,43 \%)$ estão na faixa dos 60 aos 69 anos de idade e 3 (menos de $1 \%$ ), na faixa dos 80 anos e mais. Notamos que 2 (menos de 1\%) referem não saber ler nem escrever; enquanto 144 (46,75\%), possuem o segundo grau e (88) 28,75\%, o nível superior (Tabela 1).

Os achados demonstram que $137(44,48 \%)$ são viúvas; $86(27,92 \%)$ são casadas e $52(16,88 \%)$ referem nunca terem casado (Tabela 1). Duzentos e cinqüenta idosas $(81,16 \%)$ tiveram filhos, a média verificada é de quatro filhos por cada idosa, sendo 
dois a média de filhas mulheres.

No arranjo domiciliar, $153(49,68 \%)$ das idosas moram com duas a cinco pessoas; 77 (25,00\%), com uma pessoa e 54 (17,53\%) moram sós (Tabela 1).

Em relação às pessoas com as quais as mulheres residem, observamos na Tabela 2 que 111 (36,04\%) moram com filhas; apenas $6(1,95 \%)$ ainda moram na companhia dos pais. Observamos ainda que 67 $(21,75 \%)$ moram na companhia de netos (com uma terceira geração). A grande maioria, 279 (90,58\%), diz-se satisfeita com suas vidas.

\section{Tabela 1}

Distribuição das 308 idosas do Programa Universidade Aberta à Terceira Idade da Universidade Federal de Pernambuco (UnATI/UFPE) em relação à faixa etária, ao nível de escolaridade, ao estado conjugal e ao arranjo domiciliar. Recife, PE.

\begin{tabular}{|c|c|c|}
\hline Variáveis & $\mathbf{N}$ & $\%$ \\
\hline \multicolumn{3}{|l|}{ Idade } \\
\hline $60-69$ & 220 & 71,43 \\
\hline $70-79$ & 85 & 27,60 \\
\hline 80 e mais & 3 & 0,97 \\
\hline \multicolumn{3}{|l|}{ Escolaridade } \\
\hline Analfabeta & 2 & 0,68 \\
\hline Primário & 64 & 20,78 \\
\hline Ginásio & 10 & 3,25 \\
\hline Segundo Grau & 144 & 46,75 \\
\hline Superior & 88 & 28,75 \\
\hline \multicolumn{3}{|l|}{ Estado conjugal } \\
\hline Viúvas & 137 & 44,48 \\
\hline Casadas & 86 & 27,92 \\
\hline Divorciadas & 33 & 10,72 \\
\hline Nunca casou & 52 & 16,88 \\
\hline \multicolumn{3}{|l|}{ Arranjo domiciliar } \\
\hline Moram com duas a cinco pessoas & 153 & 49,68 \\
\hline Moram com uma pessoa & 77 & 25,00 \\
\hline Moram com seis a dez pessoas & 20 & 6,49 \\
\hline Moram sós & 54 & 17,53 \\
\hline Moram com mais de dez pessoas & 4 & 1,30 \\
\hline
\end{tabular}


Tabela 2

Distribuição das 308 idosas do Programa Universidade Aberta à Terceira Idade da Universidade Federal de Pernambuco (UnATI/UFPE) em relação ao grau de parentesco entre a idosa e as pessoas com as quais reside. Recife, PE.

\begin{tabular}{|c|c|c|c|c|c|c|}
\hline Atividades & Sim & $\%$ & Não & $\%$ & NA* & $\%$ \\
\hline Cônjuge & 82 & 26,63 & 172 & 55,84 & 54 & 17,53 \\
\hline Pais & 6 & 1,95 & 248 & 80,52 & 54 & 17,53 \\
\hline Filhos & 95 & 30,85 & 159 & 51,62 & 54 & 17,53 \\
\hline Filhas & 111 & 36,04 & 143 & 46,43 & 54 & 17,53 \\
\hline Irmãos & 33 & 10,72 & 221 & 71,75 & 54 & 17,53 \\
\hline Netos & 67 & 21,75 & 187 & 60,72 & 54 & 17,53 \\
\hline Outro familiar & 54 & 17,53 & 200 & 64,93 & 54 & 17,53 \\
\hline Outro não parente & 50 & 16,23 & 204 & 66,24 & 54 & 17,53 \\
\hline
\end{tabular}

NA = não se aplica: estas são as idosas que moram sós.

\section{Necessidade de cuidados e de utilização de órteses e próteses}

Quanto à utilização de órteses e/ou próteses, 293 $(95,13 \%)$ utilizam óculos e/ou lentes de contato e apenas $7(2,27 \%)$ utilizam aparelho auditivo. As mulheres na quase totalidade, são independentes quanto à deambulação, e apenas uma (menos de $1 \%$ ), refere utilizar ajuda técnica do tipo bengala.
Perguntadas sobre caso viessem a ficar doentes ou incapacitadas, quais as pessoas que poderiam dispensar-lhes cuidados, $131(42,53 \%)$ referem ser a filha; $26(8,44 \%)$ referem ser o cônjuge. Chama a atenção a proporção de mulheres, $15(4,87 \%)$ referindo que não contariam com ninguém e $11(3,57 \%)$ referindo que não sabem com quem contar em caso de doença e/ou incapacidade (Tabela 3).

Tabela 3

Distribuição das 308 idosas do Programa Universidade Aberta à Terceira Idade da Universidade Federal de Pernambuco (UnATI/UFPE) em relação à utilização de órteses/próteses e em relação a pessoas que poderiam cuidá-las em caso de doença e/ou incapacidades. Recife, PE.

\begin{tabular}{lcc}
\hline Variáveis & N & \\
& & $\%$ \\
\hline Utilização de órteses e/ou próteses & 281 & 293 \\
$\quad$ Dente postiço, dentadura, ponte & 7,23 \\
Óculos ou lente de contato & 1 & 95,13 \\
Aparelho para surdez & 2,27 \\
Bengala & 0,32 \\
& 131 & 48 \\
Pessoas que poderiam cuidá-las em caso de doença e/ou incapacidade & 41 \\
Filha & 36 \\
Outra pessoa da família que não cônjuge e filhos & 15,59 \\
Filho & 26 \\
Alguém de fora da família (ex: auxiliar de enfermagem) & 13,31 \\
Cônjuge & 11,69 \\
Não contariam com ninguém & 11 & 8,44 \\
Não sabem com quem contar & 4,87 \\
\hline
\end{tabular}




\section{Atividades de vida diária}

As mulheres entrevistadas referem capacidade para desempenhar, sem ajuda, quase a totalidade das atividades investigadas, sendo a única exceção cortar as unhas dos pés, onde $46(14,94 \%)$ declaram-se incapazes para fazê-lo sozinhas e estão entre os 60 e 69 anos de idade. Considerando condições mínimas de autonomia e independência, tarefas do tipo comer, vestir-se, pentear-se e escovar os cabelos, deitar na cama e levantar dela, tomar banho, $100 \%$ das mulheres dizem-se capazes de realizá-las sozinhas e sem ajuda. Duas (menos de 1\%), referem dificuldade para preparar sua própria refeição. Já no item realizar atividades domésticas/manter a casa em ordem, 17 $(5,52 \%)$ idosas referem não realizar essa atividade sem ajuda (Tabela 4).

Tabela 4

Distribuição das 308 idosas do Programa Universidade Aberta à Terceira Idade da Universidade Federal de Pernambuco (UnATI/UFPE) em relação ao grau de autonomia e independência no desempenho das atividades de vida diária (AVD). Recife, PE.

\begin{tabular}{|c|c|c|c|c|c|c|}
\hline Quem* & Sim & $\%$ & Não & $\%$ & $N A * *$ & $\%$ \\
\hline Sair para média distância - necessita transporte & 301 & 97,73 & 7 & 2,27 & --- & --- \\
\hline Sair para pequena distância - compra/armazém & 304 & 98,70 & 4 & 1,30 & --- & --- \\
\hline Preparar sua própria refeição & 306 & 99,35 & 2 & 0,64 & --- & --- \\
\hline Realizar atividade doméstica - manter/ordem & 291 & 94,48 & 17 & 5,52 & --- & --- \\
\hline Tomar seus remédios & 302 & 98,05 & 2 & 0,65 & 4 & 1,30 \\
\hline Comer sua comida & 308 & 100,00 & --- & --- & --- & --- \\
\hline Vestir-se sozinho & 308 & 100,00 & --- & --- & --- & --- \\
\hline Pentear / escovar seus cabelos & 308 & 100,00 & --- & --- & --- & --- \\
\hline Caminhar em superfície plana & 307 & 99,68 & 1 & 0,32 & --- & --- \\
\hline Subir escadas & 294 & 95,45 & 14 & 4,55 & --- & -- \\
\hline Deitar e levantar da cama sozinho & 308 & 100,00 & --- & -- & --- & --- \\
\hline Tomar banho sozinha & 308 & 100,00 & --- & --- & --- & --- \\
\hline Cortar as unhas dos pés & 262 & 85,06 & 46 & 14,94 & --- & --- \\
\hline Pegar ônibus & 299 & 97,08 & 9 & 2,92 & --- & --- \\
\hline Ir ao banheiro em tempo & 306 & 99,35 & 2 & 0,65 & --- & --- \\
\hline
\end{tabular}

*Variáveis não mutuamente exclusivas; ** NA = não se aplica (categoria acrescentada para atender a resposta "não tomo remédios")

A ocupação do tempo livre é adequada, e a maior parte das idosas refere realizar quase todas as tarefas listadas. No entanto, quanto às atividades rela- cionadas à prática esportiva, apenas $16(5,19 \%)$ declaram praticarem esportes (Tabela 5). 
Distribuição das 308 idosas do Programa Universidade Aberta à Terceira Idade da Universidade Federal de Pernambuco (UnATI/UFPE) em relação às atividades realizadas no tempo livre. Recife, PE.

\begin{tabular}{|c|c|c|c|c|}
\hline Atividades* & Sim & $\%$ & Não & $\%$ \\
\hline Ouvir rádio & 226 & 73,38 & 82 & 26,62 \\
\hline Assistir a televisão & 289 & 93,83 & 19 & 6,17 \\
\hline Ler jornal & 248 & 80,52 & 60 & 19,48 \\
\hline Ler revistas e livros & 255 & 82,79 & 53 & 17,21 \\
\hline Receber visitas & 260 & 84,42 & 48 & 15,58 \\
\hline Ir ao cinema, teatro, etc. & 146 & 47,40 & 162 & 52,60 \\
\hline Andar pelo bairro & 267 & 86,69 & 41 & 13,31 \\
\hline Ir à igreja (serviços religiosos) & 271 & 87,98 & 37 & 12,02 \\
\hline Ir a jogos (esportes) & 36 & 11,69 & 272 & 88,31 \\
\hline Participar de jogos (esportes) & 16 & 5,19 & 292 & 94,81 \\
\hline Fazer compras & 296 & 96,10 & 12 & 3,90 \\
\hline Sair para visitar os amigos & 267 & 86,69 & 41 & 13,31 \\
\hline Sair para visitar os parentes & 280 & 90,91 & 28 & 9,09 \\
\hline Sair / passeio longo (excursão) & 228 & 74,03 & 80 & 25,97 \\
\hline Sair / encontro social/comunitário & 212 & 68,83 & 96 & 31,17 \\
\hline Coser, bordar, tricotar & 198 & 64,61 & 109 & 35,38 \\
\hline Atividade / distração: cartas, xadrez, jardim & 132 & 42,85 & 176 & 57,14 \\
\hline
\end{tabular}

* Variáveis não mutuamente exclusivas.

\section{Condições socioeconômicas}

A interação social é adequada, $238(77,27 \%)$ das idosas mostram-se satisfeitas no relacionamento mantido com as pessoas com as quais residem; 270 $(87,66 \%)$ estão satisfeitas no relacionamento com vizinhos e $304(98,70 \%)$ no relacionamento com os amigos (Tabela 6).

Tabela 6

Distribuição das 308 idosas do Programa Universidade Aberta à Terceira Idade da Universidade Federal de Pernambuco (UnATI/UFPE) em relação à convivência com as pessoas com quem residem, com amigos e vizinhos. Recife, PE.

\begin{tabular}{lcccccc}
\hline Pessoas & Satisfeitas & $\%$ & Insatisfeitas & $\%$ & NA* & $\%$ \\
\hline Com quem residem & 238 & 77,27 & 16 & 5,20 & 54 & 17,53 \\
Amigos & 304 & 98,70 & 4 & 1,30 & -- & -- \\
Vizinhos & 270 & 87,66 & 17 & 5,52 & 21 & 6,82 \\
\hline
\end{tabular}

* NA = não se aplica (mulheres idosas que moram sós). 
De modo geral, não há dependência das entrevistadas em relação aos seus familiares. Mais importante do que o aspecto financeiro e de moradia, em que $209(67,86 \%)$ e $238(77,27 \%)$, respectivamente, não dependem da família, foi referida pela maioria 233 (75,32\%), a companhia e o cuidado pessoal, como os aspectos em que os familiares se fazem mais presentes. As idosas referem-se ainda como provedoras em potencial de seus familiares. Assim 267 $(86,69 \%)$ oferecem à família companhia e cuidado pessoal; $171(53,52 \%)$ oferecem moradia e 183 $(59,42 \%)$ assistência financeira. Outro item demonstra um tipo de ajuda que em geral as idosas oferecem - cuidar de criança - onde $122(39,61 \%)$, o fazem (Tabela 7)

Em relação às visitas recebidas na última semana (tendo como base a data da entrevista), 219 $(71,10 \%)$, referem que são visitadas por vizinhos e amigos, e 194 (62,98\%), pelos filhos (Figura 1).

\section{Tabela 7}

Distribuição das 308 idosas do Programa Universidade Aberta à Terceira Idade da Universidade Federal de Pernambuco (UnATI/UFPE) em relação à assistência oferecida pela família à idosa e em relação à assistência que a idosa oferece à família. Recife, $\mathrm{PE}$.

\begin{tabular}{|c|c|c|c|c|}
\hline Variáveis & Sim & $\%$ & Não & $\%$ \\
\hline \multicolumn{5}{|l|}{ Assistência oferecida pela família à idosa } \\
\hline Dinheiro & 99 & 32,14 & 209 & 67,86 \\
\hline Moradia & 70 & 22,73 & 238 & 77,27 \\
\hline Companhia / Cuidado Pessoal & 233 & 75,32 & 76 & 24,68 \\
\hline Outro tipo de cuidado assistência & 82 & 26,62 & 226 & 73,38 \\
\hline \multicolumn{5}{|l|}{ Assistência que a idosa oferece à família } \\
\hline Dinheiro & 183 & 59,42 & 125 & 40,58 \\
\hline Moradia & 171 & 53,52 & 137 & 44,48 \\
\hline Companhia / Cuidado Pessoal & 267 & 86,69 & 41 & 13,31 \\
\hline Cuidar de criança & 122 & 39,61 & 186 & 60,39 \\
\hline Outro tipo de cuidado assistência & 71 & 23,05 & 237 & 76,95 \\
\hline
\end{tabular}

Figura 1

Distribuição das 308 idosas do Programa Universidade Aberta à Terceira Idade da Universidade Federal de Pernambuco (UnATI/UFPE) em relação às visitas recebidas na última semana. Recife, PE.

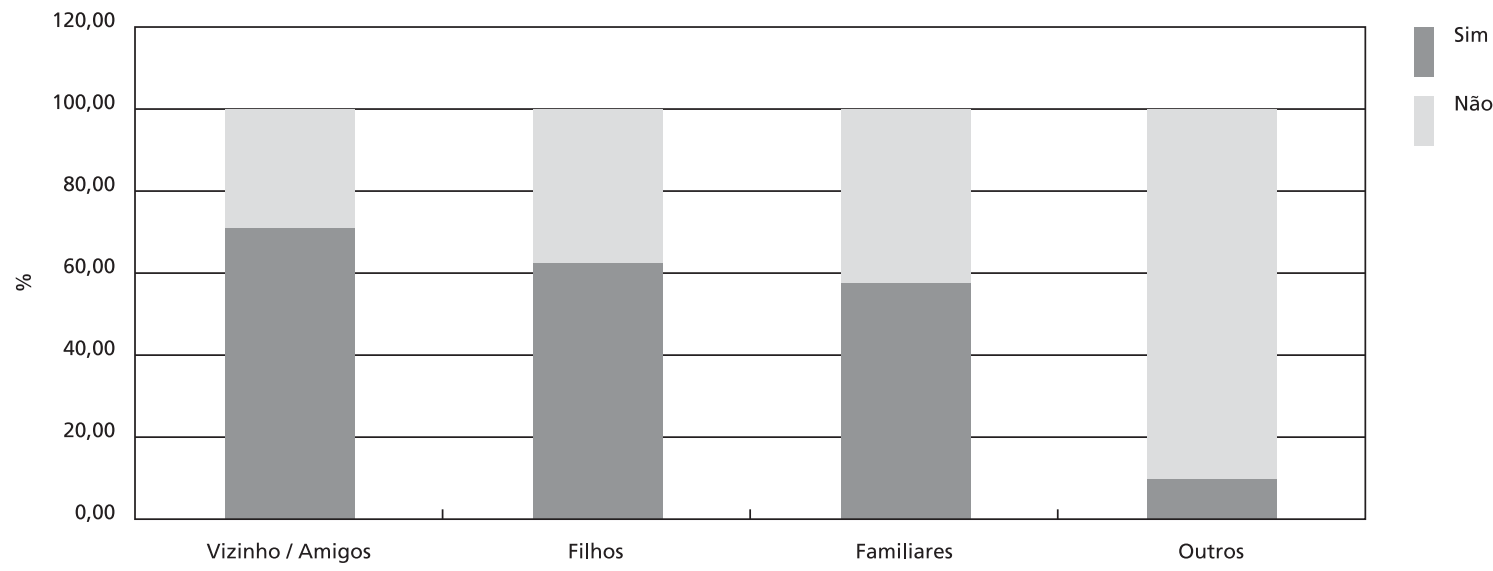


Sobre o tipo de trabalho que realizaram por mais tempo em suas vidas, o de dona de casa foi referido por $123(39,95 \%)$ mulheres; o trabalho administrati- vo em instituições privadas foi o menos referido, apenas 18 (5,84\%) (Figura 2). Trinta e duas mulheres, $(10,39)$ ainda permanecem trabalhando.

Figura 2

Distribuição das 308 idosas do Programa Universidade Aberta à Terceira Idade da Universidade Federal de Pernambuco (UnATI/UFPE) em relação ao tipo de trabalho que realizaram por mais tempo em suas vidas. Recife, PE.

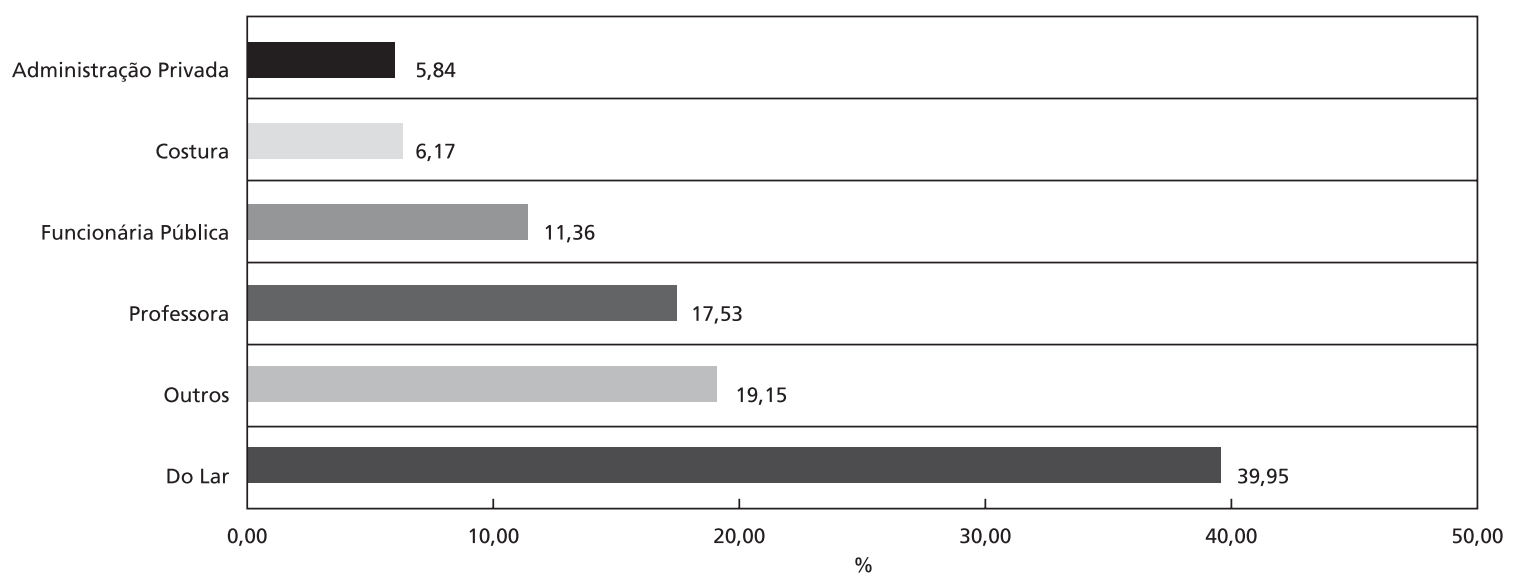

A maior parte das idosas $287(93,18 \%)$ refere possuir algum tipo de renda; apenas $17(5,52 \%)$ das entrevistadas referem não terem renda própria e 4 $(1,30 \%)$ não responderam (Figura 8). Entre as 287 que referem possuir renda $194(67,60 \%)$ recebem aposentadoria e $135(47,04 \%)$, pensão do cônjuge. Cento e trinta e quatro $(43,50 \%)$, dizem que sua renda é suficiente para suprir suas despesas.

Utilizamos o salário mínimo como parâmetro para expressar a distribuição da renda familiar das idosas. Entre as 247 que referiram renda familiar, 65 $(26,32 \%)$ informam ser entre sete e dez salários mínimos; 40 (16,19\%), acima de vinte salários mínimos e 2 (menos de $1 \%$ ) declaram renda familiar inferior a um salário mínimo (Tabela 8).
Tabela 8

Distribuição das 308 idosas do Programa Universidade Aberta à Terceira Idade da Universidade Federal de Pernambuco (UnATI/UFPE) em relação à renda das 247 famílias que a possuem, tomando como parâmetro o salário mínimo. Recife, PE.

\begin{tabular}{lrr}
\hline Salário(s) mínimo & Total & $\%$ \\
\hline Menos de um & 2 & 0,81 \\
1 a 3 & 25 & 10,12 \\
4 a 6 & 40 & 16,19 \\
7 a 10 & 65 & 26,32 \\
11 a 15 & 38 & 15,39 \\
16 a 20 & 37 & 14,98 \\
Mais de 20 & 40 & 16,19 \\
Total & 247 & 100,00 \\
\hline
\end{tabular}


As entrevistadas contam com condições favoráveis de moradia, tais como: água encanada, eletricidade, ligação com rede de esgotos e geladeira, além de a maioria possuir televisão, rádio e telefone. Observamos que 58 idosas $(18,83 \%)$ dizem possuir computador. Quanto à condição de residência, a maioria 232 (75,32\%), é proprietária do imóvel onde reside; 38 (12,34\%) moram em residên- cia cedida sem custo e $27(8,77 \%)$ residem em moradia alugada (Tabela 9).

Quando comparam sua situação econômica atual com a da época em que tinham cinqüenta anos de idade, $131(42,53 \%)$ acreditam que hoje a situação está melhor, enquanto a proporção entre as que acreditam ser a mesma ou estar pior se equivalem, $88(28,57 \%)$ e $89(28,90 \%)$, respectivamente.

Tabela 9

Distribuição das 308 idosas do Programa Universidade Aberta à Terceira Idade da Universidade Federal de Pernambuco (UnATI/UFPE) em relação à situação de residência e em relação a algumas condições do domicílio. Recife, PE.

\begin{tabular}{lrr}
\hline Variáveis & N & $\%$ \\
\hline Situação de residência & & $\%$ \\
Própria & 232 & 75,32 \\
Cedida & 38 & 12,34 \\
Alugada & 27 & 8,77 \\
Do cônjuge & 5 & 1,62 \\
Outra & 6 & 1,95 \\
& & \\
Algumas condições do domicílio & 304 & 98,70 \\
Água encanada & 308 & 100,00 \\
Eletricidade & 276 & 89,61 \\
Ligação com a rede de esgotos & 307 & 99,68 \\
Geladeira/congelador & 298 & 96,75 \\
Rádio & 306 & 99,35 \\
Televisão & 201 & 65,26 \\
Videocassete & 58 & 18,83 \\
Computador & 277 & 89,94 \\
Telefone & 152 & 49,35 \\
Automóvel & &
\end{tabular}

\section{Discussão}

\section{Situação pessoal e familiar}

Os resultados deste estudo, comparados com perfis de outras experiências de Universidades Abertas, guardam muita semelhança. Na UnATI/UFPE, $86,03 \%$ dos participantes são do sexo feminino, o que demonstra resultado semelhante ao de pesquisas realizadas nas Universidades da Terceira Idade na França (UTIs), no Projeto Senior da Universidade Estadual Paulista (UNESP), em um estudo comparativo entre idosos de Universidade Aberta, tanto pública quanto privada, na Universidade Aberta à
Terceira Idade da Universidade Estadual do Rio de Janeiro (UnATI/UERJ) e na Universidade Aberta para a Terceira Idade do Maranhão (UNITI).9,11-14

$\mathrm{O}$ envelhecimento por sexo e idade observado no Brasil segue o mesmo padrão visto em países desenvolvidos. 15,16 Dados demográficos, do Brasil e de muitos países, demonstram que a proporção feminina de idosas de uma população aumenta, conforme aumenta a idade. $9,12,16,17$ Essa realidade também foi observada no Recife. 4

Neste estudo e nas experiências análogas aqui referidas, a proporção de mulheres idosas em relação aos homens idosos cresce bastante, uma vez que os homens procuram menos esse tipo de participação 
em programas especiais. Várias são as explicações para esse fato: as mulheres ficam viúvas e mais solitárias na terceira idade; já os homens tendem a outro casamento; tradicionalmente, os homens resistem a engajar-se em atividades de cunho mais cultural, educacional e lúdico. Portanto, ações destinadas à população idosa devem considerar o universo feminino na terceira idade e suas peculiaridades. 15,17

A população estudada apresenta, em sua maioria $(71,43 \%)$, o que se denomina de jovens idosos, compreendidos entre a faixa dos 60-69 anos de idade. 15 Esse padrão de participação de jovens idosos por nós encontrado está consonante com os achados para as demais experiências de Universidades Abertas aqui referidas. $9,11,13,14$

A julgar que, para freqüentarem programas como o da UnATI/UFPE, é necessário competência e manejo razoáveis em termos de desempenho das atividades instrumentais de vida diária (AIVD), as quais possuem um nível de complexidade maior que as atividades de vida diária e que, com o aumento da idade aumenta proporcionalmente o aparecimento de algum grau de dependência, tanto nas AVDs quanto nas AIVDs, é compreensível a maior freqüência de idosos jovens que estão com sua capacidade funcional preservada. A composição etária observada em populações de Universidades Abertas reflete não apenas a composição etária da população geral, como também que os usuários de serviços desse tipo tendem a apresentar melhores condições econômicas, de saúde e de mobilidade do que a média dos idosos. 11

Segundo Ramos, 18 idosos com maior dependência para o desempenho das AVDs apresentam um risco três vezes maior de morrer, do que aqueles mais autônomos e independentes. Portanto, ações de promoção e manutenção da autonomia e independência, bem como educação para o autocuidado são estratégias importantes a serem desenvolvidas com a população de idosos da UnATI/UFPE.

O nível de escolaridade aqui encontrado demonstra uma diferenciação do grupo, no que se refere ao nível de instrução da população idosa em geral. As idosas estudadas possuem, em sua maioria, segundo e terceiro graus. Os estudos de Veras e Camargo Jr${ }^{11}$ e de Peixoto ${ }^{9}$ apontam resultados semelhantes. Cinquienta e três por cento das pessoas entre 60-69 anos são analfabetas e entre aquelas com 70 anos e mais esse índice é de 44\%.19 A maior parte dos idosos possui pouca educação formal. ${ }^{15,17}$ A faixa onde se encontra a mais baixa proporção de alfabetização é na de pessoas acima dos 60 anos. 15

Quando consideramos os idosos da população do país como um todo, essa coorte de idosos de hoje vem de uma época em que o acesso à educação era precário. ${ }^{19}$ Assim, essa diferenciação no nível educacional das idosas aqui estudadas as coloca com maior chance de enfrentar a velhice do que a população idosa em geral e, em particular, em relação à população idosa feminina, pois a organização social do início do século XX privilegiava o acesso à educação a uma elite social e particularmente aos homens. ${ }^{15,17}$ Hoje, as mulheres idosas estão sós e com menos possibilidades de lidarem com as dificuldades de sua velhice, principalmente pela insuficiência de políticas públicas a elas destinadas. ${ }^{15,17}$

Quanto ao estado conjugal, a maioria das idosas encontra-se entre viúvas e casadas, dados semelhantes aos encontrados por Veras e Camargo Jr, ${ }^{11}$ Goldman 13 e Carneiro. 14

O estado civil das idosas estudadas corrobora achados demográficos do Brasil e das Américas, onde ser mulher em idade avançada reflete em seu estado civil, ou seja, ser viúva.16,17 Neste estudo, quase a metade das mulheres é viúva, pouco mais de um quarto encontra-se casada e 16,88\% referiram nunca terem casado. Em relação a esse último dado, $7,6 \%$ das mulheres chegam à terceira idade solteiras, podendo chegar à velhice sem apoio de maridos e/ou filhos, o que se torna mais grave, caso venham a desenvolver perda da capacidade funcional.17 As chances da viuvez aumentam para as mulheres, à medida que a idade avança, diminuindo, pois, a oportunidade de um segundo casamento, principalmente com homens mais jovens. 15

A maior longevidade das mulheres, associada a um conjunto de fatos históricos de caráter sociocultural, que determinam que as mulheres se casem com homens mais velhos (em média três anos), acabam favorecendo um maior número de mulheres viúvas, (chegando a 3,6 para 1), além do que as mulheres descasadas e viúvas casam-se novamente menos que os homens nas mesmas situações. O resultado são períodos de solidão mais longos para as mulheres viúvas. ${ }^{7,17}$

$\mathrm{O}$ fato de as idosas deste estudo terem tido filhos coloca para elas uma possibilidade de rede de ajuda em caso de alguma necessidade. Para Peixoto, ${ }^{9}$ as mulheres que não estão casadas têm opção de arranjos domiciliares, que variam desde morar com filho ou filha solteiros, com filho casado ou com outras pessoas não pertencentes à sua família. A autora atribui esse fato ao forte vínculo afetivo entre mães e filhos e que por isso estes têm mais disponibilidade de cuidar das mães idosas. Berquó15 refere que 50\% das mulheres moram sós. Para a autora, a proporção de mulheres, a partir dos 65 anos de idade, vivendo 
sozinha aumenta com a idade.

No grupo estudado, observamos que, quanto ao arranjo domiciliar, o aspecto morar só chama a atenção, pois $17,53 \%$ das idosas apresentam-se nessa condição, mesmo que, segundo Peixoto, ${ }^{9}$ isso possa refletir as transformações ocorridas na estrutura familiar dos últimos anos, não significando, necessariamente, abandono ou isolamento. Sabemos, também, que essa condição pode constituir-se em algum nível de risco para o idoso e, portanto, é um dado muito importante para ser analisado em conjunto com outras informações referentes à autonomia e independência e também à rede de suporte social.

Ao compararmos os resultados deste estudo com os referidos por Berquó ${ }^{19}$ para a população geral, em que $8,26 \%$ das pessoas de 60 anos moram sós, observamos que os achados para as idosas da UnATI/UFPE chegam ao dobro. Peixoto, ${ }^{9}$ na UnATI/UERJ, encontrou $37 \%$ vivendo sós, enquanto Goldman, 13 na universidade privada, encontrou que quase a metade dos participantes mora só e na universidade pública, um quarto dos participantes também mora só. Percebemos que, à medida que se particulariza o grupo, a proporção de idosos vivendo só aumentou em relação à população idosa em geral. Peixoto9 refere que, em seus achados para a UnATI/UERJ, a proporção de idosos que mora só aumenta à medida que avança a idade, pois, entre as pessoas de até 69 anos, $33 \%$ moram sós e esse número cresce para $45 \%$, quando elas têm 70 anos e mais.

\section{Necessidade de cuidados e de utilização de órteses e próteses}

As únicas ajudas/apoios que as idosas da UnATI/UFPE referem fazer uso são óculos e próteses dentárias. Esse fato demonstra indiretamente o alto grau de independência desse grupo. Vale ressaltar que, atualmente, em gerontologia, as atenções voltam-se cada dia mais para as ajudas técnicas, ou dispositivos de ajuda, que convencionalmente estão sendo denominados de tecnologia assistiva. São equipamentos para auto-ajuda, que podem ser adquiridos e/ou construídos para aumentar, manter e melhorar a vida funcional das pessoas com algum grau de incapacidade e também facilitam o cotidiano dos cuidadores. 20 Esses equipamentos seguem um nível de complexidade compatível com o grau de dependência de cada usuário. Portanto, a indicação adequada de dispositivos de ajuda para idosos com algum grau de dependência significa estar promovendo e preservando sua capacidade funcional e, conseqüentemente, sua saúde.

Em caso de necessidade de cuidados, a figura da filha aparece, para as idosas do nosso censo, como sendo a pessoa eleita para dispensar-lhes esse cuidado, caso venham a ficar doentes ou incapacitadas. Em seguida, crêem poderem ser cuidadas por outra pessoa da família, depois aparecem, com percentuais semelhantes, o filho e alguém fora da família. O cônjuge é citado, porém em menor escala. Quando se referem a alguém fora da família, trata-se sempre de um profissional, que pode ser de enfermagem (enfermeiro ou auxiliar), ou ainda um leigo. Os profissionais, nesse caso, seriam contratados, sendo, portanto, externos ao arranjo familiar.

A questão do cuidado ao idoso é preocupante e permite-nos diversas reflexões. Primeiro a crença das idosas de que a filha irá dispensar-lhes cuidados e, nesta crença, está embutida uma cobrança. Mais uma vez, retomamos a função feminina do cuidado para com os idosos, lembrando que há uma grande chance de que esta filha esteja inserida no mercado de trabalho, tenha sua própria família e com filhos demandando cuidados. Essa é uma função tradicionalmente ligada à mulher, e o fato de não serem recompensadas financeiramente passa a exigir novas formas de administração dessa questão, principalmente nos grandes centros urbanos. ${ }^{7}$ A maior parte dos cuidadores domiciliares é mulher e isto alerta para o fato de que o ato de cuidar do outro, no caso, a mulher cuidadora, não é, como se concebe, tarefa natural da mulher, mas sim uma construção histórico-social, que se dá, essencialmente, na família. Portanto, cuidar não é condição natural da mulher. 21

Outra crença observada é a de que poderão contratar um profissional de enfermagem para o cuidado, seja ele de nível superior ou não. Colocam-se aqui duas questões importantes: a primeira a de que há carência de formação, tanto em nível superior quanto em nível médio, sobre geriatria e gerontologia para os profissionais da enfermagem e de outras categorias profissionais; a segunda que diz respeito ao custo desses serviços que é muito alto, além de ser uma atividade em geral, de longa duração. Portanto, esses dois fatores implicam necessariamente o aumento do valor da remuneração. Nesse caso, essa crença vira mito. Algumas ainda referem a possibilidade de contratar um leigo para essa tarefa, apontando um desconhecimento da necessidade de formação para o cuidado com idosos. É como se essa fosse uma tarefa simples, que qualquer um pudesse desempenhar. As pessoas que cuidam de idosos são denominadas, na área da geriatria e gerontologia, de cuidadores, sendo que, de acordo com o grau de dependência do idoso, haverá a necessidade de um cuidador melhor qualificado.

A população idosa atual vem de um tempo em 
que a família, no caso a família ampliada, com convivência multigeracional (avós, filhos, tios, primos ...), tinha um papel importante na vida das pessoas e assegurava o cuidado dos seus membros. 22 Essa referência, tudo indica, se concretiza quando as idosas esperam ser cuidadas por membros da família. Com o declínio da família ampliada e a estruturação da família nuclear, fica claro que o cuidado em família torna-se cada vez mais difícil.

O cenário da família nuclear em relação ao cuidado dos seus membros, em particular do idoso, é conhecido como sendo a síndrome de insuficiência familiar, ou seja, o não dispor dessa possibilidade de cuidado pode trazer para o idoso situações de morbidade de caráter físico, psíquico ou social. Um dos tipos dessa síndrome é a do filho único, referida inclusive, como sendo endêmica, pois há uma tendência mundial de famílias muito pequenas, que têm um único filho. Aqui se observa uma impossibilidade física de prestação de cuidados a seus idosos dependentes, não se tratando, pois, de rejeição, mas de impossibilidade real que acaba culminando na institucionalização. 22

Entre as idosas estudadas 3,57\% não sabem com quem contar em caso de uma necessidade desse tipo e $4,87 \%$ acreditam não poderem contar com ninguém. Isso significa que $8,44 \%$ não identificam possibilidade de ajuda em caso de doença e/ou incapacidade, reafirmando a chance de as mulheres envelhecerem sós e não terem a quem buscar para cuidar delas. O caminho mais comum acaba sendo a institucionalização. Na verdade, não seria esse o maior problema se contássemos com um sistema de institucionalização geriátrica, hierarquicamente organizado, equipado e humanizado, que atendesse ao idoso em sua integralidade. Em algumas situações, a institucionalização é a intervenção mais adequada, porém ela se dá muitas vezes por falta de opção, ou seja, por ainda não termos a total implementação da Política Nacional do Idoso e, no caso das instituições, por falta de uma política pública que oriente, regule e fiscalize as instituições geronto-geriátricas no país.

\section{Atividades de vida diária}

As idosas deste estudo são autônomas e independentes, na medida em que referem capacidade para desempenharem sozinhas e sem ajuda, a maioria das atividades de vida diária perguntadas, exceto para cortar as unhas dos pés, onde 14,94\% declaram-se sem condições para fazê-lo sozinhas.

Diversos estudos apontam que a maioria da população idosa apresenta-se com boa capacidade fun- cional e vivendo na comunidade. ${ }^{2,23}$ Nesse grupo, o nível de independência máximo está presente, praticamente, na totalidade do grupo.

A capacidade funcional no idoso é mensurada a partir do grau de autonomia e independência. $\mathrm{O}$ conceito de saúde na terceira idade, hoje postulado, diz respeito à sua capacidade funcional, ou seja, mesmo na presença de patologia, se o indivíduo consegue manter um bom nível de funcionalidade para o desempenho de suas AVDs e AIVDs, ele é um idoso saudável, independente e autônomo.

$\mathrm{Na}$ presença de apenas uma condição patológica, $5 \%$ da população idosa referem necessidade de ajuda para uma ou mais AVDs, ou seja, 95\% dos idosos, mesmo diante de uma patologia, mantêm sua capacidade funcional. Esse percentual cresce à medida que aumenta o número de doenças associadas, chegando a $65 \%$ entre as mulheres, ou seja, quando há mais de uma patologia presente, o percentual de idosos com algum nível de dependência para a realização de alguma AVD cresce de 5\% para $65 \%$ nas mulheres. 24 Portanto, o grupo aqui estudado apresenta um bom nível de saúde, tendo-se como parâmetro sua capacidade funcional.

Com relação à dificuldade para cortar as unhas dos pés, é importante esclarecermos que se trata de uma atividade complexa para a sua realização. Ao analisá-la é possível perceber que há exigências de habilidade e destreza, mobilidade corporal, força muscular, coordenação motora, coordenação visomanual, manejo de objeto cortante e boa acuidade visual, entre outras. Ao mesmo tempo, observa-se que o cuidado com os pés e as unhas do idoso vai além de um princípio básico de higiene, sendo condição importante para a sua saúde. Pés e unhas bem cuidados auxiliam a boa marcha, evitam cortes, ressecamento e endurecimento maior das unhas. Cuidar bem dos pés e unhas exige, também, segundo Knackfuss, ${ }^{25}$ a escolha de calçados adequados que não machuquem e que previnam e/ou possibilitem a correção, ou minimizem, as deformidades existentes.

Observamos um bom nível de sociabilização e adequada ocupação do tempo livre entre as idosas deste estudo. Há uma variação de tarefas desempenhadas que vão desde assistir à televisão até viagens longas, passando por atividades artísticas, culturais e religiosas. Verificamos uma menor participação nas atividades relacionadas à prática esportiva, pois as idosas declaram maciçamente não praticarem esportes.

O fato de a maioria dos idosos encontrar-se, de algum modo, desobrigada das tarefas do trabalho remunerado ou doméstico concede-lhes um grande período de tempo livre, que tende, cada vez mais, a 
ser ocupado com atividades de lazer, ou seja, atividades que permitem o descanso, divertimento, recreação e entretenimento e, ainda, o desenvolvimento pessoal. Entre as opções que possibilitam essa vivência às pessoas idosas estão as Universidades Abertas à Terceira Idade, onde a possibilidade de desenvolvimento pessoal coloca-se imperativa. Infelizmente, o lazer ainda é visto de maneira preconceituosa nas sociedades regidas pela produtividade, daí a dificuldade de alguns idosos de encontrar maneiras de ocupação adequada ao tempo livre, além do desconhecimento do benefício dessa prática para o seu bem-estar. ${ }^{26}$

\section{Condições socioeconômicas}

As mulheres deste estudo mantêm uma boa interação social. A maioria delas mostra-se satisfeita com o relacionamento mantido com as pessoas com as quais reside, com vizinhos e com os amigos.

Observamos que, de modo geral, não há dependência das entrevistadas em relação aos seus familiares, porém, entre as idosas que dependem de algum aspecto da família, a ajuda financeira é a mais referida. Elas se referem também como provedoras em potencial de seus familiares, contribuindo em termos financeiros e de moradia. Ajudar a família cuidando das crianças é referido e denota esse papel desempenhado pela idosa na família, que, se por um lado é muito importante, à medida que permite o contato intergeracional, por outro, pode constituir-se em uma obrigação para liberar filhas e noras para o mercado de trabalho, o que pode comprometer sua autonomia para administrar o seu tempo.

Os idosos, no Brasil, independentemente do gênero e condição social, participam ativamente da receita doméstica e sua renda pode representar até $45 \%$ do orçamento familiar. À medida que a idade avança, essa participação diminui e perde mais valor a partir dos 75 anos de idade. 27

Ainda em relação à dependência econômica de mulheres idosas, é importante observar que o grupo de idosas da UnATI/UFPE apresenta uma situação bastante diferente da experienciada pela maioria das idosas dos países onde não há um bom sistema de previdência social, como é o caso do Brasil. Nesses países, a maioria, está fadada a depender economicamente de terceiros, ou seja, dos mais jovens, principalmente as mais velhas, que, como já vimos, estarão viúvas, com pouca ou nenhuma escolaridade, e que, em geral, não possuem outros recursos. Acabam, assim, constituindo um grupo especialmente vulnerável. 17

A maioria das idosas costuma receber visitas de amigos e familiares (principalmente dos filhos). Essas relações fortalecem a experiência de grupo e favorecem a ampliação das relações interpessoais. Nesse sentido, novamente a rede social assume importância, pois é a partir dela que se responde a muitas demandas da população idosa. A experiência da UnATI/UFPE tem colocado a possibilidade de ampliação das relações sociais das idosas, uma vez que, a cada curso, conhecem novas pessoas e os encontros têm extrapolado o campus da UFPE, originando novos amigos e grupos sociais.

$\mathrm{O}$ fato de as idosas deste estudo pertencerem a uma coorte onde o papel fundamental da mulher era principalmente o cuidado da casa e da família justifica que a função de dona-de-casa tenha predominado, quando se lhes foi indagado o tipo de trabalho exercido na maior parte do tempo de sua vida. Um percentual de 10,39\% ainda permanece trabalhando. Ressalte-se que, no Brasil, em torno de $30 \%$ a $40 \%$ das mulheres entre 50 a 60 anos trabalham. 27 Só após 1955 é que a mão de obra feminina foi incorporada com algum relevo no mercado de trabalho, porém, em atividades que exigiam pouca escolaridade e experiência. 28

Os resultados em relação à renda demonstram que apenas 5,52\% das entrevistadas referem não ter renda própria. Entre aquelas que possuem renda, a maior parte recebe aposentadoria, ou seja, foram pessoas que tiveram acesso ao mercado formal de trabalho. Os achados deste estudo são, em parte, consonantes com os referidos por Prata e Saad 29 para a população idosa da Grande São Paulo, em que 45\% dos idosos são aposentados, ou seja, tiveram acesso ao mercado formal de trabalho. Para as mulheres, a situação é pior, pois há um percentual muito grande de sem rendimentos. Esse não é o caso da população feminina aqui estudada.

A renda familiar (tomando como parâmetro o salário mínimo) das idosas deste censo é elevada quando comparada à população idosa aposentada $\mathrm{e}$ geral: $26,32 \%$ recebem entre sete e dez salários mínimos e $16,19 \%$ entre quatro a seis ou mais de vinte.

Quando comparamos nossos resultados com os encontrados por Peixoto 9 para a UnATI/UERJ, percebemos que, aqui, os dados não se eqüivalem, sendo o nível econômico das idosas da UnATI/UFPE mais alto, dado importante por tratar-se da região Nordeste, onde o poder aquisitivo é um dos mais baixos do país. Essa diferenciação no padrão econômico do grupo de idosas da UnATI/UFPE pode se dever às características do Programa, pois alguns dos cursos oferecidos, tais como: introdução à informática, educação em saúde, nutrição e envelhecimento, leitura dinâmica, entre outros, exigem maior 
nível de escolaridade, e, para a população brasileira, maior nível de escolaridade implica melhores condições socioeconômicas. No entanto, Goldman $1^{3}$ encontrou para universidade da terceira idade privada, um nível econômico ainda mais alto que o encontrado em nosso estudo; para a universidade pública os resultados se equivalem aos nossos. Acrescentese a esse fato que a maioria das idosas estudadas na UnATI/UFPE, ao comparar sua atual situação econômica com o período em que tinham 50 anos, acredita que está melhor.

As condições de moradia referidas são favoráveis. Quase a totalidade das idosas conta com água encanada, ligação com rede de esgotos, geladeira, televisão, rádio e telefone. Todas referiram possuir eletricidade. O computador pode ser considerado pouco utilizado, quando comparado aos demais itens, porém, olhando, de um outro prisma ele aparece de modo relevante, pois $18,83 \%$ referem possuí-lo, mesmo considerando que a informatização mais ampla é um processo recente, e que o uso doméstico do microcomputador é mais recente ainda, basicamente da década de 90 . Esse é um equipamento que praticamente não fez parte da atividade de trabalho das idosas estudadas. Portanto, o número de idosas que possuem computador nesse grupo é importante, denotando um interesse pelo conhecimento do novo, o que constitui igualmente um indicativo de interação social, pois hoje a linguagem da informática faz-se necessária em diversas dimensões das nossas vidas, facilitando, inclusive, a comunicação intergeracional.

A diferenciação socieconômica do grupo de idosas estudadas evidencia-se quando observamos que a maioria reside em moradia própria e que apenas $8,77 \%$ residem em moradia alugada.

Peixoto 9 refere resultados semelhantes e afirma que, para os idosos por ela estudados, o sonho da casa própria foi alcançado em bairros mais distantes, em subúrbios, e que também o grupo se beneficiou do sistema financeiro de habitação, que há tempos era mais justo. A autora reforça que o fato de terem seu próprio imóvel os torna menos dependentes dos filhos, e, assim, procuram outras formas de status social, como freqüentar uma universidade.

Observamos que participar da Universidade Federal de Pernambuco, através do Programa Universidade Aberta à Terceira Idade é, sem dúvida, uma condição de status social, cujas experiências de coletividade caminham no sentido de responder às necessidades do novo cenário demográfico e epidemiológico. Nesse sentido, enfatizamos o papel da Universidade na implantação e implementação das políticas públicas pertinentes.

\section{Conclusões}

O perfil sócio-epidemiológico demográfico das idosas da UnATI/UFPE, mostra-se bastante semelhante ao de outras universidades para terceira idade. Portanto, este estudo apresenta as seguintes conclusões, quanto:

À situação pessoal e familiar. São um grupo de idosas-jovens, casadas e/ou viúvas, com bom nível de escolaridade. A maioria teve filhos e refere satisfação com a vida em geral.

À necessidade de cuidados e de utilização de órteses e próteses. Limitam-se às dentárias e às visuais. Crêem que, em caso de doença e/ou incapacidade, poderão contar, principalmente, com os cuidados dispensados pela filha;

Às atividades de vida diária. Gozam de bom nível de autonomia e independência funcional, desempenham as atividades de vida diária sem ajuda; ocupam o tempo livre com atividades variadas, tanto no domicílio, quanto fora dele, além de atividades ligadas à arte, cultura e lazer, com as quais se sentem satisfeitas;

Às condições socioeconômicas. Mantêm boas relações interpessoais com aqueles com os quais residem, com os amigos e com vizinhos; são, em algumas situações (moradia e finanças), provedoras de suas famílias; ou recebem dessas ajuda financeira, companhia e cuidado pessoal, o que as faz sentiremse muito bem. Recebem visitas de vizinhos, amigos e familiares; possuem renda própria proveniente de aposentadoria e/ou pensão do cônjuge. Residem em imóvel próprio e com boas condições de moradia, contando com rede de esgotos e energia elétrica.

O perfil aqui apresentado, em muitos aspectos, não reflete a realidade da população idosa de Pernambuco e aproxima-nos da realidade das idosas que procuram programas do tipo Universidades Abertas à Terceira Idade, e que se constituem, de fato, em uma coorte importante para futuras investigações na área do envelhecimento.

Por apresentarem as idosas aqui estudadas boa capacidade funcional, este estudo aponta para a importância do desenvolvimento, por parte do Programa, de atividades que visem à educação para o autocuidado. É também de grande importância que se encontrem maneiras para a ampliação das atividades do Programa, de modo a contemplar idosas socioeconomicamente menos privilegiadas. 


\section{Referências}

1. Debert GG. As representações (estereótipos) do papel do idoso na sociedade atual. In: Seminário Internacional Envelhecimento Populacional: uma agenda para o final do século; 1996 jul 1-3; Brasília, (DF), Brasil. Brasília (DF): Ministério da Previdência e Assistência Social; 1996. p. 35-45.

2. Kalache A, Ramos, LR, Veras RP. O envelhecimento da população mundial. Um desafio novo. Rev Saúde Pública 1987; 21: 200-10.

3. Silvestre JA, Kalache A, Ramos LR, Veras RP. O envelhecimento populacional brasileiro e o setor saúde. Arq Geriatr Gerontol 1996; (1): 81-9.

4. IBGE (Instituto Brasileiro de Geografia e Estatística). Censo demográfico, 2002: dados preliminares. Rio de Janeiro; 2002. Disponível em URL: Http://www.ibge.org.br [2002 abr 8].

5. Carvalho EMF, Lessa F, Gonçalves FR, Silva JAM, Lima MEF, Melo Jr SW. O processo de transição epidemiológica e iniqüidade social: o caso de Pernambuco. Rev Assoc Saúde Pública Piauí 1998; 1: 107-19.

6. Ramos LR. Explosão demográfica da terceira idade no Brasil: uma questão de saúde pública. Gerontologia 1993; 1: 3-8.

7. Veras RP. Atenção preventiva ao idoso: uma abordagem de saúde coletiva. In: Papaléo Netto M. Gerontologia: a velhice e o envelhecimento em visão globalizada. São Paulo: Atheneu; 1996. p. 383-93.

8. Brasil. Lei $\mathrm{n}^{\circ} 8.842,4$ de Janeiro de 1994. Dispõe sobre a política nacional do idoso, cria o Conselho Nacional do Idoso e da outras providências. Dia Ofic Rep Fed Brasil 1994 jan.5; Col. 2: 77.

9. Peixoto C. De volta às aulas ou de como ser estudante aos 60 anos. In: Veras RP, organizadora. Terceira idade: desafios para o terceiro milênio. Rio de Janeiro: RelumeDumará; 1997. p. 41-74.

10. Barreto KML. Universidade aberta à terceira idade. In: Congresso Brasileiro de Geriatria e Gerontologia; 1997 5-9 dez; Rio de Janeiro, RJ. Rio de Janeiro: Universidade do Estado do Rio de Janeiro; 1997.

11. Veras RP, Camargo Jr KR. Idosos e universidade: parceria para a qualidade de vida. In: Veras RP, Camargo Jr KR, organizadores. Terceira idade: um envelhecimento digno para o cidadão do futuro. Rio de Janeiro: Relume-Dumará; Universidade do Estado do Rio de Janeiro; 1995. p. 11-27.

12. Telarolli Jr R, Machado JCMS, Carvalho F. Educação em saúde na terceira idade: avaliação de um programa de extensão universitária. Gerontologia 1997; 5: 55-65.

13. Goldman SN. A política brasileira e os alunos de universidades para terceira idade. In: Congresso Brasileiro de Geriatria e Gerontologia; 1997 5-9 dez; Rio de Janeiro, RJ. Rio de Janeiro: Universidade do Estado do Rio de Janeiro; 1997.
14. Carneiro EMD. A universidade aberta como uma ação estratégica para a terceira idade: apontamentos para a compreensão dessa prática educativa [especialização]. São Luiz: Universidade Federal do Maranhão; 1998.

15. Berquó E. A mulher e a terceira idade. In: Pereira DM, organizador. Idoso: encargo ou patrimônio? São Paulo: Proposta Editorial; 1992. p. 26-8.

16. Veras RP. País jovem com cabelos brancos: a saúde do idoso no Brasil. Rio de Janeiro: Relume Dumará; 1994.

17. OPS (Organización Panamericana de la Salud), OMS (Organización Mundial de la Salud). El envejecimiento de la población mundial. Washington (DC): La Organización; 1999.

18. Ramos LR, organizador. Palestra de abertura. In: Oficina de Trabalho da Política Nacional de Saúde do Idoso: versão preliminar; 1999 abril; Brasília (DF).

19. Berquó E. Envelhecimento populacional no Brasil e suas conseqüências. In: Pereira DM, organizadora. Idoso: encargo ou patrimônio? São Paulo: Proposta Editorial; 1992. p. 51-9.

20. Abreu VPS. Produção e adaptação de ambientes dispositivos de ajuda. In: Consensos de Gerontologia do $1^{\circ}$ Congresso Paulista de Geriatria e Gerontologia; 1998 jun 2427; São Paulo, SP. São Paulo: Sociedade Brasileira de Geriatria e Gerontologia; 1998. p. 81-91.

21. Silva IP. As relações de poder no cotidiano de mulheres cuidadoras. In: Karsch UMS, organizador. Envelhecimento com dependência: revelando cuidados. São Paulo: EDUC; 1998. p. 147-70

22. Leme LEG, Silva PSCP. O idoso e a família. In: Papaléo Netto M. Gerontologia: a velhice e o envelhecimento em visão globalizada. São Paulo: Atheneu; 1996. p. 92-7.

23. Ministério de Sanidad y Consumo. Indicadores de la salud: tercera evaluación en España del Programa Regional Europeo de Salud para Todos. Madrid; El Ministério; 1995.

24. Chiovatto J. Reabilitação em geriatria. In: Papaléo Netto M. Gerontologia: a velhice e o envelhecimento em visão globalizada. São Paulo: Atheneu; 1996. p. 324-30.

25. Knackfuss IG. O pé do idoso: aspectos ortopédicos. Arq Geriatr Gerontol 1996; (1):103-6.

26. Ferrari MAC. Lazer e ocupação do tempo livre na terceira idade. In: Papaléo Netto M. Gerontologia: a velhice e o envelhecimento em visão globalizada. São Paulo: Atheneu; 1996. p. 98-105.

27. Terceira idade. Visor IPEA [Instituto Pesquisa Econômica e Aplicada] 1999; 3: 2-3.

28. Boutique NC, Santos RLA. Aspectos socieconômicos do envelhecimento. In: Papaléo Netto M. Gerontologia: a velhice e o envelhecimento em visão globalizada. São Paulo: Atheneu; 1996. p. 82-91.

29. Prata L, Saad P. Caracterização socieconômica e demográfica do idoso na grande São Paulo. In: Pereira DM. Idoso: encargo ou patrimônio? São Paulo: Proposta Editorial; 1992. p.18

Recebido em 2 de agosto de 2002

Versão final apresentada em 4 de fevereiro de 2003

Aprovado em 28 de maio de 2003 